\title{
Associations of subclinical hypocalcemia with fertility in a herd of grazing dairy cows
}

\author{
Sebastián Umaña Sedó, ${ }^{*}$ Diana Rosa, $†$ Guillermo Mattioli, $\uparrow$ R. Luzbel de la Sota, $¥ \S$ \\ and Mauricio J. Giuliodori $\dagger^{1}$ \\ *Private practice, Cañuelas, B1814, Argentina \\ †Cátedra de Fisiología, Facultad de Ciencias Veterinarias, Universidad Nacional de La Plata (FCV-UNLP), B1900AVW, La Plata, Argentina \\ ‡Cátedra y Servicio de Reproducción Animal, FCV-UNLP, B1900AVW, La Plata, Argentina \\ §Comisión Nacional de Investigaciones Científicas y Tecnológicas (CONICET), C1033AAJ, Buenos Aires, Argentina
}

\section{ABSTRACT}

The main objective was to assess the associations of subclinical hypocalcemia $(\mathrm{SCH})$, diagnosed at parturition (SCH-0) and $7 \mathrm{~d}$ in milk (SCH-7), with fertility in a herd of grazing dairy cows. Additional objectives were to characterize $\mathrm{Ca}$ concentration on 0 and $7 \mathrm{~d}$ in milk (DIM), assessing the risk factors for SCH-0 and $\mathrm{SCH}-7$ and also the relationship with health status (metritis, endometritis, subclinical ketosis, and culling). A prospective observational study was carried out in a dairy farm in Argentina. Holstein cows $(\mathrm{n}=126)$ were body condition scored (BCS, 1-5) on $-21 \pm 3,0$, $7 \pm 3$, and $28 \pm 7$ DIM and blood was collected on 0 and $7 \pm 3$ DIM to determine Ca and $\beta$-hydroxybutyrate concentrations. Calcium concentrations $<2.0$ and $<2.14$ $\mathrm{mmol} / \mathrm{L}$ were used to define $\mathrm{SCH}-0$ and $\mathrm{SCH}-7$, respectively. The associations of SCH with (1) the odds for pregnancy to first service (P1AI) and pregnancy by 100 DIM (P100) were evaluated by logistic models, (2) the services per pregnancy was evaluated by a Poisson regression model, and (3) the hazards of insemination and pregnancy were evaluated with proportional hazards regression models whereas median days from calving to first insemination and to pregnancy were estimated by Kaplan-Meier method. Additionally, Ca concentration was assessed by linear regression models, and the associations of SCH- 0 and SCH-7 with the odds for metritis, endometritis, subclinical ketosis, and culling were evaluated by logistic models. Calcium concentrations were similar at 0 and 7 DIM (2.40 vs. $2.41 \mathrm{mmol} / \mathrm{L}$, respectively); they were higher in cows calving in fall than in summer (2.58 vs. $2.24 \mathrm{mmol} / \mathrm{L})$, and they also were higher in primiparous than in multiparous cows ( 2.53 vs. $2.28 \mathrm{mmol} / \mathrm{L}$, respectively). The proportion

\footnotetext{
Received December 4, 2017.

Accepted June 4, 2018.

${ }^{1}$ Corresponding author: mauriciog@fcv.unlp.edu.ar
}

of cows having SCH-0 and SCH-7 was 27.3 and $39.3 \%$, respectively. Fall-calving cows had lower odds for SCH0 [odds ratio $(\mathrm{OR})=0.31,95 \%$ confidence interval $(\mathrm{CI})$ $=0.12-0.86]$ than summer-calving cows, multiparous cows had higher odds for SCH-0 (OR $=3.96,95 \%$ CI $=1.09-14.39$ ) than primiparous cows, and cows with prepartum BCS $\geq 3.00$ had higher odds for SCH-0 (OR $=4.03,95 \% \mathrm{CI}=1.17-13.89)$ than in cows with $\mathrm{BCS}$ $<3.00$. Conversely, parity and prepartum BCS were not important predictors for SCH-7. Surprisingly, SCH-0 was not a risk factor for SCH-7. Cows with SCH-0 had lower odds for P1AI $(\mathrm{OR}=0.26,95 \% \mathrm{CI}=0.07-0.99)$ than normocalcemic cows, given that P1AI was 14 versus $38 \%$, respectively. The hazard of first service was not associated with $\mathrm{SCH}-0$ (hazard ratio $=1.03$, $95 \% \mathrm{CI}=0.63-1.70)$ but cows with SCH-0 had lower hazard of pregnancy (hazard ratio $=0.39,95 \% \mathrm{CI}=$ 0.16-0.98) and took $32 \mathrm{~d}$ longer to get pregnant (105 vs. 73) than normocalcemic cows. Conversely, SCH-7 was not associated with fertility. Finally, SCH-0 and $\mathrm{SCH}-7$ were associated with the odds for subclinical ketosis and metritis, respectively. In conclusion, $\mathrm{SCH}-0$ but not SCH-7 is associated with reduced fertility in a herd of grazing dairy cows, but both were associated with health status.

Key words: subclinical hypocalcemia, pregnancy risk, fertility, grazing dairy cow

\section{INTRODUCTION}

Before calving, dairy cows require approximately 30 $\mathrm{g}$ of $\mathrm{Ca} / \mathrm{d}$ (15 $\mathrm{g}$ for fetuses) that is mainly provided by passive gastrointestinal absorption (DeGaris and Lean, 2008). However, at parturition, as the concentration of $\mathrm{Ca}$ in colostrum and milk is 30- and 10-fold higher than in blood $(62-75$ vs. $25-30$ vs. $2.2-2.5 \mathrm{mmol} / \mathrm{L}$, respectively), the requirement may exceed $50 \mathrm{~g} / \mathrm{d}$ (Horst et al., 2005). This increased Ca demand must be satisfied by active gastrointestinal absorption and bone resorption (DeGaris and Lean, 2008). As the homeo- 
static mechanisms involving active gastrointestinal Ca absorption and active bone Ca mobilization have a lag time to take effect (>48 h; Martín-Tereso and Martens, 2014), most cows experience some degree of hypocalcemia at calving (DeGaris and Lean, 2008). Depending on the severity of the blood Ca decrease, some cows (approximately 5\%) can develop clinical hypocalcemia, whereas most of them (30 up to 70\%) show no clinical signs despite having hypocalcemia [i.e., subclinical hypocalcemia (SCH); Reinhardt et al., 2011]. The associations of clinical hypocalcemia with milk production, reproductive performance, and health status of dairy cows have extensively been studied (Curtis et al., 1983, 1984, 1985), whereas the associations of subclinical cases with performance have received less attention (Goff, 2008; Murray et al., 2008).

Recently, studies have focused on this topic with inconsistent results. Some found negative associations with indicators of reproductive performance (Martinez et al., 2012, 2016; Caixeta et al., 2017), whereas others reported no association (Chamberlin et al., 2013; Gild et al., 2015; Rodríguez et al., 2017). These discrepancies could partly be the result of differences in the study design (i.e., timing of diagnosis and cut-point used; Neves et al., 2017). No consensus exists as to when and how to objectively assess $\mathrm{SCH}$, and this lack of standardization of SCH classification may affect our ability to establish associations between $\mathrm{SCH}$ and fertility (Neves et al., 2018). Likewise, most recent studies have been performed in confinement herds in North America and Europe, and information about the associations of $\mathrm{SCH}$ with fertility of dairy cows under grazing production systems is lacking (Ribeiro et al., 2013).

Our main objective was to assess the associations of SCH at 0 (SCH-0) and 7 DIM (SCH-7) with fertility in a herd of grazing dairy cows (i.e., odds for pregnancy and hazard of pregnancy). Additional objectives were to characterize $\mathrm{Ca}$ concentration at 0 and 7 DIM, assess the risk factors for $\mathrm{SCH}-0$ and $\mathrm{SCH}-7$, and, finally, evaluate the associations of $\mathrm{SCH}-0$ and $\mathrm{SCH}-7$ with health status.

\section{MATERIALS AND METHODS}

\section{Farm Management}

The current study was conducted on a commercial dairy farm located in Cañuelas, Buenos Aires Province, Argentina $\left(35^{\circ} 05^{\prime} \mathrm{S}\right.$ and $\left.58^{\circ} 75^{\prime} \mathrm{W}\right)$. The herd consisted of Holstein cows $(\mathrm{n}=2,000)$ that were milked in 4 milking parlors (i.e., 500 cows each). Prepartum transition cows that were within $3 \mathrm{wk}$ of expected calving date were maintained on dry lots, fed $15 \mathrm{~kg}$ of corn silage, $5 \mathrm{~kg}$ of wheat hay, $7 \mathrm{~kg}$ of distilled barley, and $5.5 \mathrm{~kg}$ of commercial balanced feed (feed composition $=30 \%$ corn, $25 \%$ wheat bran, $38 \%$ soybean meal, and $7 \%$ anionic salts; chemical composition $=88 \% \mathrm{DM}, 17 \% \mathrm{CP}, 2.7$ Mcal of ME $/ \mathrm{kg}$ DM, $2.65 \%$ ether extract, $12.80 \%$ ash, $2.25 \% \mathrm{Ca}, 0.85 \% \mathrm{P}, 1.26 \% \mathrm{Mg}, 0.05 \% \mathrm{Na}$, and $2.01 \%$ $\mathrm{Cl})$. The target DCAD was -10 to $-15 \mathrm{mEq} / 100 \mathrm{~g}$ of DM. Cows were monitored for signs of calving by farm employees trained to assist parturition. After calving, cows were sent for $20 \mathrm{~d}$ to the fresh herd at pasture. Lactating cows were at pasture in a rotational system (different paddock in the morning and afternoon). Feed was composed of mixed pastures (lucerne, red clover, ryegrass, tall fescue) and winter annual grasses (oats) and supplemented with TMR diets (16 kg of corn silage, $3 \mathrm{~kg}$ of lucerne hay, and $3 \mathrm{~kg}$ of wheat bran) formulated to meet or exceed the NRC (2001) nutrient requirements for lactating Holstein cows weighing 650 $\mathrm{kg}$ and producing $30 \mathrm{~kg}$ of milk (3.5\% fat). Finally, 2 $\mathrm{kg}$ of concentrates (40\% soybean pellets and $60 \%$ corn meal) were offered twice daily during milking. Average milk yield was $8,000 \mathrm{~kg} /$ lactation. Calving occurred year round, except for the hot summer months (January and February). Lactating cows were milked twice daily at 0200 and 1400 h. Farm veterinarians visited the farm routinely every month to conduct reproductive examinations. After a voluntary waiting period of $40 \mathrm{~d}$, cows were checked for estrus twice daily and AI by the same technician with the am/pm rule. Estrus detection was facilitated by tail painting. Cows were considered in estrus when over $50 \%$ of tail paint was removed. An Ovsynch protocol was used for cows not bred within 100 DIM. Pregnancy was diagnosed by ultrasonography between 28 and $32 \mathrm{~d}$ postinsemination. Pregnant cows were rechecked by ultrasonography at approximately 90 $\mathrm{d}$ of gestation. Relevant data were managed with herd management software Protambo Master 3.0 (DIRSA SA, Gonnet, Argentina).

\section{Study Design, Study Population, Clinical Examination, and Sampling}

No protocol of animal use was required, but the experiment was conducted in a manner that avoided unnecessary discomfort to the animals by the use of proper management and sample and data collection techniques. A prospective observational study was carried out in 1 milking parlor by including all cows calving on Monday to Wednesday between December 21, 2016, and June 21, 2017. Sample size $(\mathrm{n}=126)$ was estimated as the number of cows needed to detect a difference of $15 \mathrm{~d}$ (with a pooled SD of $30 \mathrm{~d}$ ) between means in the interval from calving to pregnancy, with 
$80 \%$ power and $95 \%$ confidence, assuming a prevalence of SCH of $50 \%$ in the study population (Dhand and Khatkar, 2014).

Cows were BCS on a scale of 1 to 5 (Ferguson et al., 1994) on $-21 \pm 3,0$ (parturition), $7 \pm 3$, and $28 \pm 7$ DIM and tail bled on 0 and $7 \pm 3$ DIM by the first author. Blood samples were collected in 10-mL polystyrene tubes without an anticoagulant, allowed to clot at room temperature for up to $6 \mathrm{~h}$, centrifuged at $2,200 \times$ $g$ for 10 min at room temperature, and serum was stored at $-20^{\circ} \mathrm{C}$ until analyzed for total Ca concentration in 1 batch. Total Ca concentration was measured by using an atomic absorption spectrophotometer (AAnalyst 200; Perkin-Elmer Inc., Shelton, CT) with the flame technique and acetylene gas. After dilution 1:50 of serum in $0.1 \%$ lanthanum, the sample was mixed thoroughly and aspirated by the machine. A hollow cathode lamp with a wavelength of 422.7 was used to detect Ca. The BHB concentration was determined cow side with a hand-held device (FreeStyle Precision, Abbott GmbH \& Co. KG, Wiesbaden, Germany; Iwersen et al., 2013). Vaginal discharge (VD) was assessed by direct inspection of the mucus obtained with Metricheck (Simcro, Hamilton, New Zealand) on $7 \pm 3$ and $28 \pm 7$ DIM (McDougall et al., 2007) and categorized as VD0 (clear normal mucus), VD1 (mucus with flecks of pus), VD2 (mucus with purulent content but not fetid), and VD3 (mucus with fetid odor; Giuliodori et al., 2013b, 2017).

\section{Disease Definitions}

Calcium concentration $<2.0 \mathrm{mmol} / \mathrm{L}(<8.0 \mathrm{mg} / \mathrm{dL})$ within $24 \mathrm{~h}$ after parturition was used to define SCH-0 (Reinhardt et al., 2011), and $\mathrm{Ca}<2.14 \mathrm{mmol} / \mathrm{L}(<8.59$ $\mathrm{mg} / \mathrm{dL}$ ) at $7 \pm 3$ DIM was used to define SCH-7 (Martinez et al., 2012). Subclinical ketosis was set at BHB concentration $\geq 1.2 \mathrm{mmol} / \mathrm{L}$ at $7 \pm 3$ DIM (LeBlanc, 2010). Cows with SCH or subclinical ketosis were not treated. Metritis was defined as VD3 at $7 \pm 3$ DIM and clinical endometritis as VD1, 2, or 3 at $28 \pm 7$ DIM (Giuliodori et al., 2013a,b, 2017).

\section{Statistical Analysis}

Characterization of $\mathrm{Ca}$ Concentration. The fixed effect of sampling day postpartum (day: 0 vs. 7 DIM), calving season (summer vs. fall), parity (1 vs. $\geq 2$ ), and their interaction, controlled by prepartum BCS (as continuous predictor), on Ca concentration was evaluated with a linear regression model with normal distribution and identity link function in Proc Glimmix (SAS/STAT ver. 9.4, SAS Institute Inc., Cary, NC). Sampling day was considered as a repeated measure by using a covariance structure of compound symmetry.
Statistical significance was set at $P<0.05$ and a tendency was declared at $P \leq 0.10$.

Risk Factors for $\boldsymbol{S C H}$. The odds for SCH-0 and $\mathrm{SCH}-7$ were assessed with binomial distribution and logit link function in Proc Glimmix. These logistic models included the fixed effects of calving season (summer vs. fall), parity ( 1 vs. $\geq 2$ ), and BCS ( $<3.00$ vs. $\geq 3.00$ ) at $21 \pm 3 \mathrm{~d}$ prepartum and at parturition. The fixed effect of SCH-0 was also included in the model assessing the odds for SCH-7. Modeling was performed by the backward elimination method with an exclusion criteria set at $P>0.1$.

$\boldsymbol{S C H}$ and Fertility. The associations of SCH-0 and SCH-7 with the odds for pregnancy to first service (P1AI) and for pregnancy by 100 (P100) were evaluated by logistic models with binomial distribution and logit link function in Proc Glimmix. Their relationship with the number of services per pregnancy (SPP) was evaluated by Poisson regression model with Poisson distribution and log link function in Proc Glimmix, and, finally, their associations with the hazards of being inseminated and of becoming pregnant were evaluated with proportional hazard regression models in Proc PHReg of SAS. All these models included SCH-0, SCH7 , and their interaction, calving season (summer vs. fall), parity ( 1 vs. $\geq 2$ ), and diseases [subclinical ketosis, metritis, and endometritis (no vs. yes)] as fixed terms. Modeling was performed by the backward elimination method with an exclusion criterion set at $P>0.1$ (with the exception of SCH-0 and $\mathrm{SCH}-7$ that were forced to remain in the model). Median days from calving to insemination and to pregnancy were estimated via a Kaplan-Meier model by using Proc Lifetest of SAS. Finally, a sensitivity analysis was performed to test the assumption of nonindependent censoring, supposing 2 extreme situations: first, assuming a complete positive correlation between right-censoring and pregnancy, so that all the right-censored cows were assumed as becoming pregnant at censoring time; and second, assuming a complete negative correlation between rightcensoring and pregnancy, so that all the right-censored cows before 150 DIM were recorded as if they were right-censored at 150 DIM.

SCH and Health Status. Logistic models assessing the odds for metritis, endometritis, subclinical ketosis, and culling included the fixed effect of SCH-0, SCH-7, and their interaction. They also included the fixed effect of calving season (summer vs. fall) and parity (1 vs. $\geq 2$ ). The model assessing the odds for endometritis also included the fixed effect of metritis and subclinical ketosis, and the model assessing the odds for culling also included the fixed effect of metritis, subclinical ketosis, and endometritis. Modeling was performed by the backward elimination method with an exclusion 
criteria set at $P>0.1$ (with the exception of $\mathrm{SCH}$ that was forced to remain in the model).

\section{RESULTS}

\section{Descriptive Statistics}

Subclinical hypocalcemia was detected in $27.3 \%$ $(34 / 126)$ and in $39.3 \%(48 / 122)$ of cows at 0 and $7 \pm 3$ DIM, respectively. No cow was diagnosed with clinical hypocalcemia. Subclinical ketosis was identified in $9.1 \%(11 / 122)$ of cows. Metritis and endometritis were diagnosed in $20.4 \%(25 / 122)$ and $26.3 \%(31 / 118)$ of cows, respectively. Finally, 20.6\% (26/126) of cows were culled (4 cows were culled between 0 and 7 DIM, 4 cows between 7 and 28 DIM, 14 cows between 28 and 100 DIM, and 4 cows were culled between 100 and 150 DIM).

The odds for SCH-0 was evaluated on 126 cows (98 multiparous and 28 primiparous). The odds for SCH-7, subclinical ketosis, and metritis at $7 \pm 3$ DIM were assessed on 122 cows, the odds for endometritis and P1AI were evaluated on 118 cows, and the odds for P100 was assessed on 104 cows. A total of 26 cows were left-censored and another 29 cows were right-censored at 150 DIM (end of study period) in the analysis of the hazard of pregnancy.

\section{Characterization of $\mathrm{Ca}$ Concentration}

Sampling day was not associated with Ca concentration (2.40 vs. $2.41 \mathrm{mmol} / \mathrm{L}$ on 0 and 7 DIM, respectively; $P=0.85$; Table 1 ). Conversely, calving season was associated with $\mathrm{Ca}$ concentration $(P<0.01)$, given that fall-calving cows had higher concentrations $(2.58$ vs. $2.24 \mathrm{mmol} / \mathrm{L}$ ) than summer-calving cows (Table 1 ). Parity was also associated with $\mathrm{Ca}$ concentration $(P$ $=0.01$ ), given that primiparous cows had higher concentrations ( 2.53 vs. $2.28 \mathrm{mmol} / \mathrm{L})$ than multiparous ones (Table 1). Interactions of sampling day by calving season, sampling day by parity, and calving season by parity were not associated with Ca concentration $(P=$ $0.38,0.30$, and 0.29 , respectively). Finally, prepartum BCS tended to be associated with Ca concentration $(P$ $=0.09)$, given that $\mathrm{Ca}$ levels decreased $0.29 \mathrm{mmol} / \mathrm{L}$ $(1.16 \mathrm{mg} / \mathrm{dL})$ per every 1 point of BCS over the mean (Table 1).

\section{Risk Factors for SCH}

Important predictors in final model assessing the odds for SCH-0 were parity, calving season, and BCS, whereas only calving season remained in the model evaluating the odds for SCH-7. The odds for SCH-0 were 4.0 times higher in multiparous cows [odds ratio $(\mathbf{O R})=3.96,95 \% \mathrm{CI}=1.09-14.39, P=0.04]$ than in primiparous cows (32 vs. 11\%, respectively). The odds was lower for cows calving in fall $(\mathrm{OR}=0.31,95 \% \mathrm{CI}$ $=0.12-0.86, P=0.02)$ than in summer (16 vs. $38 \%$, respectively). Also, the odds were 4.0 times higher in cows with prepartum $\mathrm{BCS} \geq 3.00(\mathrm{OR}=4.03,95 \% \mathrm{CI}=$ $1.17-13.89, P=0.03)$ than in cows with BCS $<3.00$ (44 vs. $19 \%$, respectively). On the other hand, the odds for $\mathrm{SCH}-7$ were also lower in fall-calving cows $(\mathrm{OR}=0.31$, $95 \% \mathrm{CI}=0.11-0.84, P=0.02)$ than in summer-calving ones (24 vs. $50.6 \%$, respectively). Conversely, the odds for SCH-7 was neither associated with parity (37.5 vs. $30.9 \%$ for parity $\geq 2$ vs. $1 ; P=0.36$ ) nor BCS at any time point $(P>0.1)$. Surprisingly, $\mathrm{SCH}-0$ was not associated with the odds for SCH-7 (OR $=0.78,95 \%$ CI $=0.26-2.35, P=0.65$ ) given that the proportion of affected cows were 33.5 and $39.2 \%$ for hypocalcemic cows and normocalcemic cows, respectively, at parturition.

\section{$\mathrm{SCH}$ and Fertility}

Cows with SCH-0 had lower odds for P1AI $(\mathrm{OR}=$ $0.26 ; P=0.04$; Table 2) and lower hazard of pregnancy [hazard ratio $(\mathbf{H R})=0.39 ; P=0.04$; Table 2] than normocalcemic cows and took $32 \mathrm{~d}$ longer to get pregnant (Figure 1), but they had similar hazard of insemination ( $\mathrm{HR}=1.03 ; P=0.90$; Table 2$)$ and similar SPP (2.5 vs. $2.0 ; P=0.21$; Table 2 ) to normocalcemic cows. On the other hand, $\mathrm{SCH}-7$ was neither associated with the odds for P1AI $(\mathrm{OR}=1.26 ; P=0.71$; Table 2$)$ and $\mathrm{P} 100(\mathrm{OR}=1.20 ; P=0.77$; Table 2$)$ nor with the hazard of insemination (HR $=1.27 ; P=0.36$; Table 2$)$ and pregnancy $(\mathrm{HR}=0.63 ; P=0.21$; Table 2$)$. Cows

Table 1. Multivariable linear regression model evaluating the associations of sampling day relative to parturition, calving season, and parity with total Ca concentration in blood in a herd of grazing dairy cows $(\mathrm{n}=126)$

\begin{tabular}{llcc}
\hline & \multicolumn{3}{c}{ Total Ca concentration ${ }^{1}(\mathrm{mmol} / \mathrm{L})$} \\
\cline { 2 - 4 } Item & LSM & SE & $P$-value \\
\hline Sampling day (DIM) & 2.40 & 0.05 & 0.85 \\
$\quad \quad$ & 2.41 & 0.06 & \\
$\quad \begin{array}{l}\text { Calving season } \\
\quad \text { Summer }\end{array}$ & 2.24 & 0.06 & $<0.01$ \\
$\quad$ Fall & 2.58 & 0.07 & \\
Parity & & & 0.01 \\
$\quad$ Primiparous & 2.53 & 0.08 & \\
Multiparous & 2.28 & 0.05 & \\
\hline
\end{tabular}

${ }^{1}$ Calcium concentration decreased $0.29 \mathrm{mmol} / \mathrm{L}(1.16 \mathrm{mg} / \mathrm{dL})$ per every increase of 1 point in BCS over the mean prepartum BCS $(P=$ 0.09 ). Sampling day by calving season, sampling day by parity, and calving season by parity had $P$-values of $0.38,0.30$, and 0.29 , respectively. 
Table 2. Multivariable logistic (pregnancy to first AI and pregnancy by 100 DIM), Poisson (services per pregnancy), and proportional hazard (hazard of 1st AI and hazard of pregnancy) regression models evaluating the associations of subclinical hypocalcemia (SCH) with fertility in a herd of grazing dairy cows $(\mathrm{n}=126)^{1}$

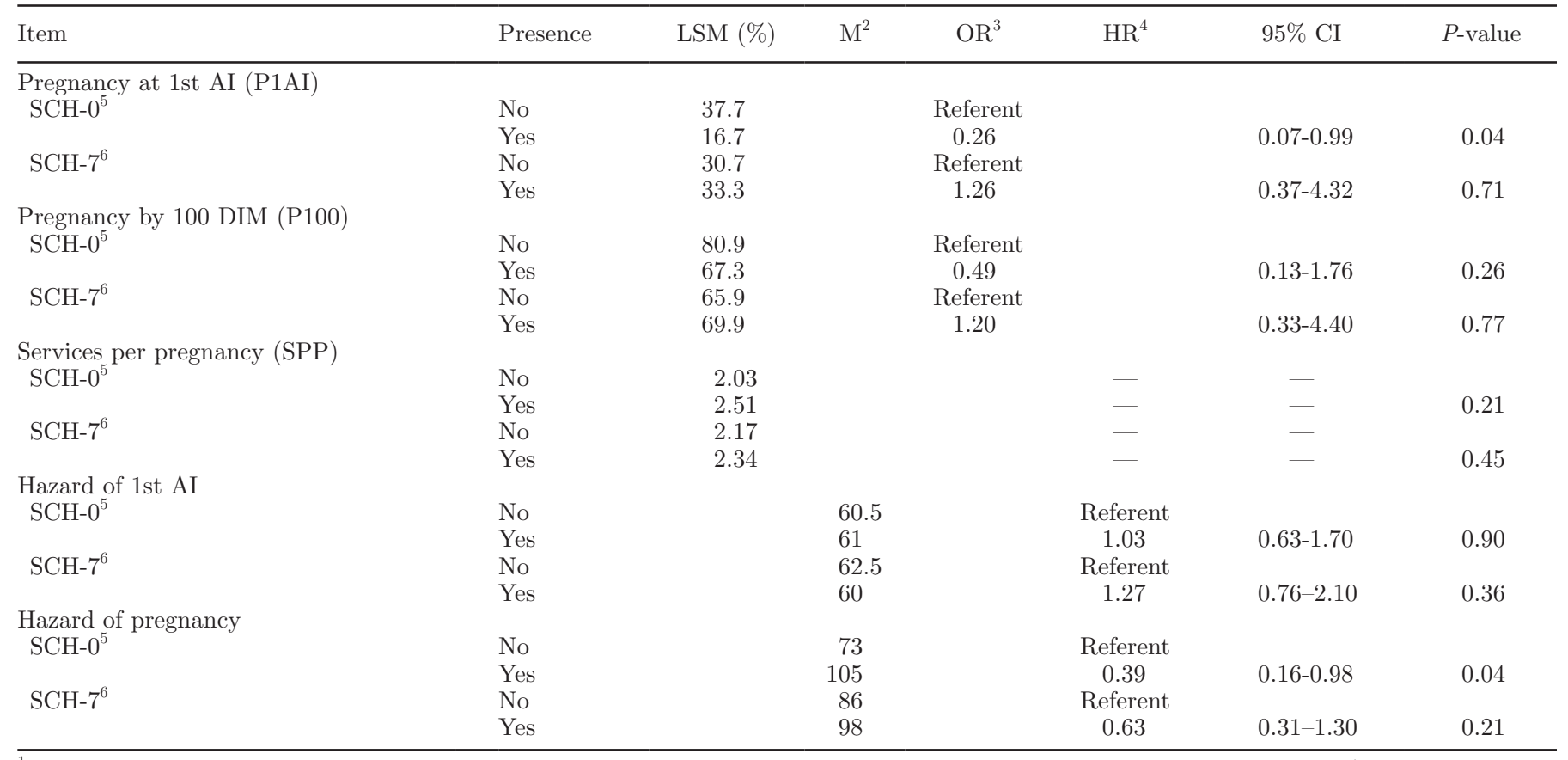

${ }^{1}$ Multivariable models were offered with the effect of SCH-0, SCH-7, SCH-0 by SCH-7, calving season, parity, and disease (subclinical ketosis, metritis, and endometritis) and manually removed if $P>0.1$. Predictors other than SCH not shown in the table. Interaction SCH-0 by SCH-7 had $P>0.1$ in final models. The only predictor that remained in models assessing P100 and hazard of pregnancy was calving season $(P<0.05$ and $P=0.04$, respectively).

${ }^{2} \mathrm{M}$ : median time (d) interval from calving to event (first AI or pregnancy).

${ }^{3} \mathrm{OR}$ : odds ratio.

${ }^{4} \mathrm{HR}$ : hazard rate.

${ }^{5} \mathrm{SCH}-0$ : subclinical hypocalcemia defined as cows having total blood Ca concentration $<2.0 \mathrm{mmol} / \mathrm{L}(<8.0 \mathrm{mg} / \mathrm{dL})$ within $24 \mathrm{~h}$ after parturition. ${ }^{6} \mathrm{SCH}-7$ : subclinical hypocalcemia defined as cows having total blood Ca concentration $<2.14 \mathrm{mmol} / \mathrm{L}(<8.59 \mathrm{mg} / \mathrm{dL}) 7 \mathrm{~d}$ after parturition.

with or without SCH-7 had similar SPP (2.36 vs. 2.18; $P=0.45$; Table 2). Finally, the interaction of SCH-0 by SCH-7 was not associated with any of the assessed reproductive parameters $(P>0.1$, Table 2$)$.

Final multivariable models also showed that calving season was associated with the odds for P100 and with the hazard of pregnancy, given that cows calving in fall had higher odds for P100 (OR $=9.10,95 \%$ CI $=$ $1.02-81.19 ; P<0.05)$ and higher daily risk for pregnancy $(\mathrm{HR}=3.26,95 \% \mathrm{CI}=1.04-10.19 ; P=0.04)$ than those calving in summer. The remaining predictors were not associated with any of the evaluated odds $(P>0.1)$.

Sensitivity analysis showed that cows with SCH had a hazard of pregnancy of 0.48 (95\% CI $=0.23-1.03)$ when assuming a complete positive correlation between right-censoring and pregnancy, whereas the analysis had a hazard of pregnancy of $0.38(95 \%$ CI $=0.02$ 2.27 ) when assuming a complete negative correlation between right-censoring and pregnancy. We speculated that if the censoring would be influenced by $\mathrm{SCH}$, the association between SCH and the hazard of pregnancy could be biased. From sensitivity analysis results, we can see that under both hypothetical scenarios the association of $\mathrm{SCH}$ with the hazard of pregnancy was similar and remained in the same direction, suggesting that the violation of nonindependent censoring is not a large concern.

\section{SCH and Health Status}

Predictors in final models were SCH-0 when measuring the odds for subclinical ketosis (Table 3), SCH-7 when evaluating the odds for metritis (Table 3), metritis when assessing the odds for endometritis, and, finally, endometritis when estimating the odds for culling. Cows with SCH-0 tended to have higher odds for subclinical ketosis $(\mathrm{OR}=6.21 ; P=0.10$; Table 3$)$ compared with normocalcemic cows. Conversely, having $\mathrm{SCH}-0$ was neither associated with the odds for metritis $(\mathrm{OR}=0.34 ; P=0.14$; Table 3$)$, endometritis $(\mathrm{OR}=0.28 ; P=0.12 ;$ Table 3$)$, and culling $(\mathrm{OR}=$ 


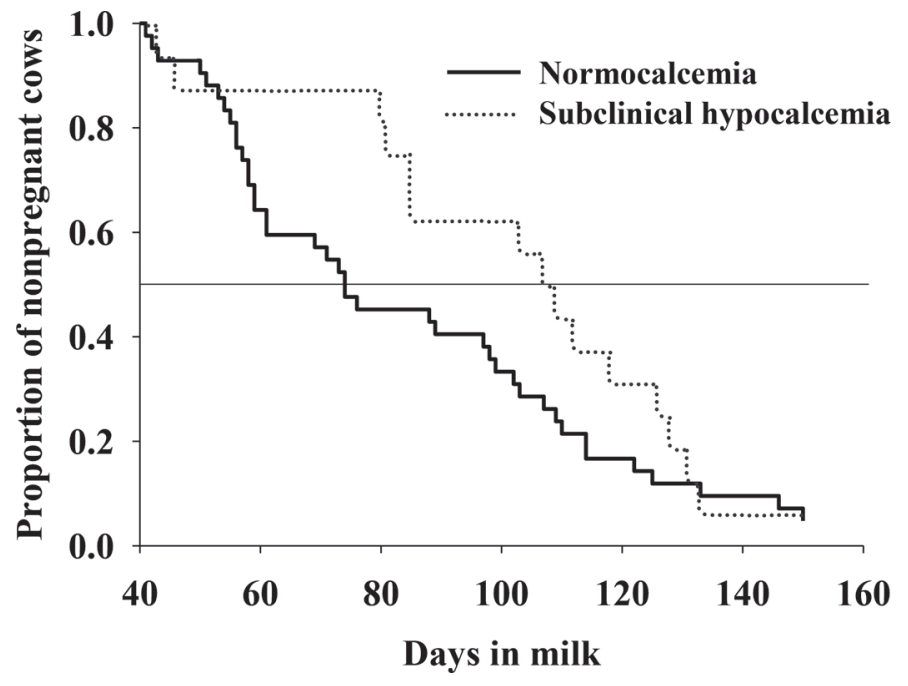

Figure 1. Subclinical hypocalcemia at parturition and the interval from calving to pregnancy in a herd of grazing dairy cows $(\mathrm{n}=126)$. Cows having subclinical hypocalcemia at parturition (defined as $<2.0$ $\mathrm{mmol} / \mathrm{L}$ ) had lower hazard of pregnancy (hazard ratio $=0.36,95 \% \mathrm{CI}$ $=0.14-0.88, P=0.03)$ and longer calving to pregnancy interval [me$\operatorname{dian}(95 \% \mathrm{CI})=105(80-125)]$ than normocalcemic cows $[73(58-97)]$.

2.47; $P=0.27$; Table 3 ) nor to the hazard of culling $(\mathrm{HR}=2.47,95 \% \mathrm{CI}=0.43-17.02 ; P=0.27)$.

On the other hand, $\mathrm{SCH}-7$ was associated with the odds for metritis $(\mathrm{OR}=5.76 ; P=0.01$; Table 3$)$, but it was associated neither with the odds for endometritis $(\mathrm{OR}=0.92 ; P=0.88$; Table 3$)$ and culling $(\mathrm{OR}=$ 2.32; $P=0.39$; Table 3) nor the hazard of culling (HR $=0.47,95 \% \mathrm{CI}=0.13-1.65 ; P=0.24)$. Finally, the interaction $\mathrm{SCH}-0$ by $\mathrm{SCH}-7$ was not associated with any of the assessed odds $(P>0.1$; Table 3$)$. Multivariable logistic models also showed that metritis was associated with the odds for endometritis $(\mathrm{OR}=3.20,95 \%$ $\mathrm{CI}=0.99-10.26 ; P=0.05)$ and that endometritis was associated with the odds for culling $(\mathrm{OR}=5.00,95 \%$ $\mathrm{CI}=1.09-22.80 ; P=0.04)$. The remaining predictors had $P>0.1$.

\section{DISCUSSION}

The main objective of the present paper was to assess the associations of $\mathrm{SCH}-0$ and $\mathrm{SCH}-7$ with reproductive performance in a herd of grazing dairy cows. Our main finding was that cows having $\mathrm{SCH}-0$, but not SCH-7, had approximately 3-fold lower odds for P1AI, 3 -fold lower hazard of pregnancy, and also a calving to pregnancy interval approximately 1 mo longer than normocalcemic cows. Our results are similar to reports that found that cows housed in confinement with $\mathrm{SCH}$ have lower odds for P1AI (Caixeta et al., 2017), or tendencies for reduced P1AI (Martinez et al., 2016)

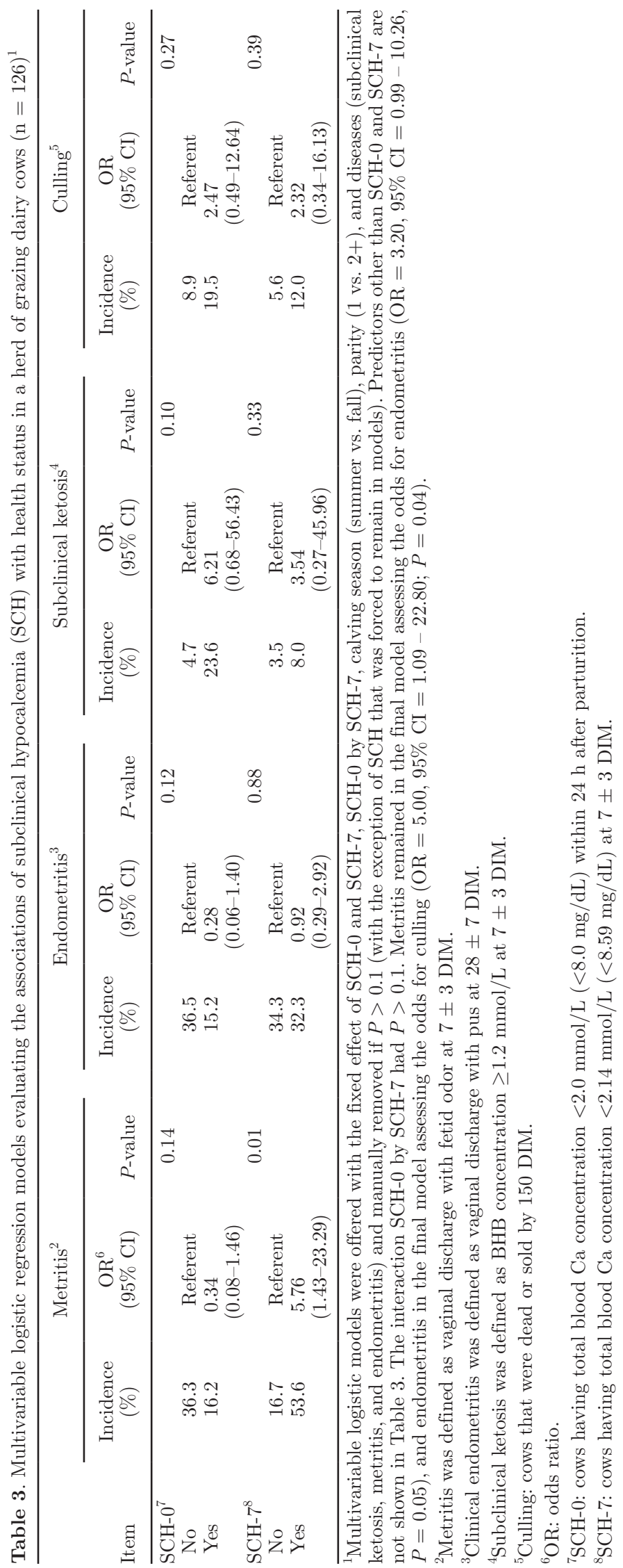


and 10 to $15 \mathrm{~d}$ longer calving to pregnancy intervals (Martinez et al., 2012, 2016). Conversely, other studies found no association with P1AI (Martinez et al., 2012; Ribeiro et al., 2013; Gild et al., 2015), calving to conception interval (Chamberlin et al., 2013; Gild et al., 2015), or the number of SPP (Chamberlin et al., 2013; Ribeiro et al., 2013; Rodríguez et al., 2017). These discrepancies could be the result of differences in the timing of diagnosis of SCH (0 through 7 DIM) and in the cut-point used to classify the cows (from 1.9-2.2 $\mathrm{mmol} / \mathrm{L}$ ), in the indicator of reproductive performance used (i.e., odds for pregnancy at first service, return to cyclicity, days open, and so on), and, finally, in the production system, given that most of the published works have been performed on confinement dairy herds; our study, however, was carried out in grazing dairy cows. Therefore, the lack of standardization of $\mathrm{SCH}$ classification makes the comparison among studies even harder (Neves et al., 2018).

Other sources of variation could be periparturient diseases because they have different incidences, different consequences on a cow's subsequent fertility, and their effects seem to be additive (Borsberry and Dobson, 1989). In fact, these additive negative effects on reproduction have also been reported for clinical and subclinical diseases (Ribeiro et al., 2013). These diseases thus have the potential to negatively affect fertility of dairy cows; therefore, they should be considered in statistical models assessing cow fertility when possible. It has been proposed that $\mathrm{SCH}$ is negatively associated with reproductive performance indirectly through delaying uterine involution (Murray et al., 2008) and impairing immunity (Kimura et al., 2006), both leading to increased risk for uterine diseases (Martinez et al., 2012) that, in turn, are associated with reduced fertility (Giuliodori et al., 2013a,b, 2017). In addition, hypocalcemia may reduce DMI postpartum (Jawor et al., 2012; Martinez et al., 2014), compromising nutrient balances including worsening the negative energy balance (Martinez et al., 2012; Chamberlin et al., 2013), which, in turn, it is associated with poorer immune function and fertility. Finally, as Ca plays a critical role in many physiological functions, it is likely that $\mathrm{SCH}$ could also exert direct detrimental effect on fertility.

In fact, evidence exists of a cross-talk between skeleton and energy metabolism involving osteocalcin, insulin, adiponectin, and leptin, among other metabolic signals (Lee et al., 2007). Osteocalcin, produced by osteoblasts and released into blood circulation by osteoclasts during bone resorption, may play an important role in homeorhetic adaptation to lactation (Lean et al., 2014). Thus, it is likely that after parturition, when osteocalcin concentration increases, the associations of bone tissue with energy metabolism, and likely with cow health, production, and reproduction, could go beyond the effect of Ca concentration alone, as previously speculated.

Regarding our additional objectives, we found that Ca concentrations were similar at 0 and 7 DIM, that they decreased with parity and with increasing prepartum BCS, and, finally, that they varied with calving season (i.e., lower in cows calving in summer than in those calving in fall). Our findings are in line with the following previous reports. Martinez et al. (2012) found similar $\mathrm{Ca}$ concentrations when comparing 0 and 7 DIM in normocalcemic cows and in cows with SCH. Kamgarpour et al. (1999) reported that cows, once recovered from the initial Ca nadir at parturition, experience a subsequent Ca nadir at 6 and 9 DIM when calving in winter and summer, respectively. In addition, Eldon et al. (1988) reported that Ca concentration decreased from autumn to summer season (2.5 vs. $2.3 \mathrm{mmol} / \mathrm{L}$ ) in lactating dairy cows. Kamgarpour et al. (1999) found higher Ca concentrations in summercalving cows than in winter-calving cows (2.26 vs. 2.17 mmol/L). Conversely, Jonsson et al. (1997) found no differences in $\mathrm{Ca}$ concentration between cows calving in summer and winter months (2.34 vs. $2.32 \mathrm{mmol} / \mathrm{L})$.

In our study, 27.3 and $39.3 \%$ of cows had $\mathrm{SCH}-0$ and $\mathrm{SCH}-7$, respectively. Reported incidences of $\mathrm{SCH}$ in grazing dairy cows were $20 \%$ (cut-point: $<2.0 \mathrm{mmol} / \mathrm{L}$, 3-7 DIM; Sepúlveda-Varas et al., 2015) and 43\% (cutpoint: $<2.14 \mathrm{mmol} / \mathrm{L}, 7 \mathrm{DIM}$; Ribeiro et al., 2013). Other studies with cows in confinement, mostly in the United States and Europe, have found an incidence of SCH ranging from $18.9 \%(<1.87 \mathrm{mmol} / \mathrm{L}, 0 \mathrm{DIM}$; Gild et al., 2015) to $78.0 \%(<2.14 \mathrm{mmol} / \mathrm{L}, 1-3$ DIM; Caixeta et al., 2017). The main reason for this high variability is likely due to the cut-point used, given that the higher the cut-point the higher the proportion of affected cows. Other possible sources of variation could be timing of diagnosis that varied from 0 to 7 DIM and those associated with management of cows (i.e., production system, nutrition, milk yield, and so on). We found that calving season was associated with the odds for SCH-0 and SCH-7 (i.e., higher odds in summer-calving cows). We also found that parity was associated with the odds for SCH-0 but not with the odds for SCH-7, consistent with Neves et al. (2017), who reported that parity is an important predictor for $\mathrm{SCH}$ at calving but not at $2 \mathrm{DIM}$, and with Martinez et al. (2012), who found that primiparous cows had higher Ca concentration than multiparous cows at calving but similar concentrations between parities from 1 to 12 DIM. A negative correlation between age and $\mathrm{Ca}$ ( $\mathrm{r}$ $=-0.23$ ) has been reported (Eldon et al., 1988), with bone and intestine vitamin $\mathrm{D}$ receptors declining with aging (Horst et al., 1990). Therefore, increased age is 
expected to play a role in the development of $\mathrm{SCH}$, but why that association is only seen at parturition remains unanswered. Finally, and surprisingly, SCH-0 was not associated with the odds for SCH-7. As far as we know, this is the first report of this lack of association between SCH-0 and SCH-7. Taken together all the above information would suggest that risk factors for $\mathrm{SCH}$ could change with timing of diagnosis.

Our results regarding the associations of SCH-0 and -7 with health status should be interpreted with caution, because sample size estimation was not based on detecting differences between proportions (it was based on detecting differences in the calving to pregnancy interval). Therefore, the power for these analyses was poor and the possibility of type II error occurrence was present. We found that SCH-0 was associated with the odds for subclinical ketosis and that $\mathrm{SCH}-7$ was associated with the odds for metritis, with other analyses showing fairly large nonsignificant associations. Other reports similarly found greater concentrations of BHB (Martinez et al., 2012), higher incidence of subclinical ketosis (Ribeiro et al., 2013), and even higher odds for clinical ketosis (Rodríguez et al., 2017) in cows with $\mathrm{SCH}$ than in normocalcemic cows. In some studies $\mathrm{SCH}$ was found to be predictive of metritis (Martinez et al., 2012; Ribeiro et al., 2013; Rodríguez et al., 2017), whereas in others such association was not found (Chamberlin et al., 2013; Neves et al., 2018) or even it acted as a protective factor (Gild et al., 2015).

Other limitations were that our study was run in only 1 herd and herd has been identified as a risk factor for SCH (Neves et al., 2017). We also lack data regarding individual milk yield because the study herd stopped running official monthly milk tests at the beginning of the experiment. A final consideration could be that time windows for $\mathrm{Ca}$ assessment were different $(1 \mathrm{~d}$ at 0 DIM vs. $7 \mathrm{~d}$ at $7 \pm 3 \mathrm{DIM}$ ), thus a wider window could be another reason why SCH-7 was not associated with certain outcomes.

\section{CONCLUSIONS}

Subclinical hypocalcemia at parturition, but not at 7 DIM, was associated with lower odds for pregnancy, lower hazard of pregnancy, and longer interval from calving to pregnancy; therefore, it is associated with poor fertility in a herd of grazing dairy cows. We suggest that it would be better to test the cows for $\mathrm{SCH}$ the day of calving than testing $7 \mathrm{~d}$ later.

\section{ACKNOWLEDGMENTS}

This study was financed by National University of La Plata (UNLP) Incentive Program (V11/230 and
V11/243) to R. L. de la Sota and G. A. Mattioli, respectively. The authors thank the farm owner and personnel for their support.

\section{REFERENCES}

Borsberry, S., and H. Dobson. 1989. Periparturient diseases and their effect on reproductive performance in five dairy herds. Vet. Rec. 124:217-219.

Caixeta, L. S., P. A. Ospina, M. B. Capel, and D. V. Nydam. 2017. Association between subclinical hypocalcemia in the first 3 days of lactation and reproductive performance of dairy cows. Theriogenology 94:1-7.

Chamberlin, W. G., J. R. Middleton, J. N. Spain, G. C. Johnson, M. R. Ellersieck, and P. Pithua. 2013. Subclinical hypocalcemia, plasma biochemical parameters, lipid metabolism, postpartum disease, and fertility in postparturient dairy cows. J. Dairy Sci. 96:7001-7013.

Curtis, C. R., H. N. Erb, C. J. Sniffen, and R. D. Smith. 1984. Epidemiology of parturient paresis: Predisposing factors with emphasis on dry cow feeding and management. J. Dairy Sci. 67:817-825.

Curtis, C. R., H. N. Erb, C. J. Sniffen, R. D. Smith, and D. S. Kronfeld. 1985. Path analysis of dry period nutrition, postpartum metabolic and reproductive disorders, and mastitis in Holstein cows. J. Dairy Sci. 68:2347-2360.

Curtis, C. R., H. N. Erb, C. J. Sniffen, R. D. Smith, P. A. Powers, M. C. Smith, M. E. White, R. B. Hillman, and E. J. Pearson. 1983 Association of parturient hypocalcemia with eight periparturient disorders in Holstein cows. J. Am. Vet. Med. Assoc. 183:559-561.

DeGaris, P. J., and I. J. Lean. 2008. Milk fever in dairy cows: A review of pathophysiology and control principles. Vet. J. 176:58-69.

Dhand, N. K., and M. S. Khatkar. 2014. Statulator: An online statistical calculator. Sample size calculator for comparing two independent means. Accessed Aug. 14, 2016. http://statulator.com/ SampleSize/ss2M.html.

Eldon, J., T. Thorsteinsson, and T. Olafsson. 1988. The concentration of blood glucose, urea, calcium and magnesium in milking dairy cows. Zentralbl. Veterinarmed. A 35:44-53.

Ferguson, J. D., D. T. Galligan, and N. Thomsen. 1994. Principal descriptors of body condition score in Holstein cows. J. Dairy Sci. 77:2695-2703.

Gild, C., N. Alpert, and M. van Straten. 2015. The influence of subclinical hypocalcemia on production and reproduction parameters in Israeli dairy herds. Isr. J. Vet. Med. 70:16-21.

Giuliodori, M. J., M. Magnasco, R. P. Magnasco, I. M. Lacau-Mengido, and R. L. de la Sota. 2017. Purulent vaginal discharge in grazing dairy cows: risk factors, reproductive performance and prostaglandin F2 $\alpha$ treatment. J. Dairy Sci. 100:3805-3815.

Giuliodori, M. J., R. P. Magnasco, D. Becu-Villalobos, I. M. LacauMengido, C. A. Risco, and R. L. de la Sota. 2013a. Metritis in dairy cows: Risk factors and reproductive efficiency. J. Dairy Sci. 96:3621-3631.

Giuliodori, M. J., R. P. Magnasco, D. Becu-Villalobos, I. M. LacauMengido, C. A. Risco, and R. L. de la Sota. 2013b. Clinical endometritis in an Argentinean herd of dairy cows: Risk factors and reproductive efficiency. J. Dairy Sci. 96:210-218.

Goff, J. P. 2008. The monitoring, prevention, and treatment of milk fever and subclinical hypocalcemia in dairy cows. Vet. J. 176:50-57.

Horst, R. L., J. P. Goff, and T. A. Reinhardt. 1990. Advancing age results in reduction of intestinal and bone 1,25-dihydroxyvitamin D receptor. Endocrinology 126:1053-1057.

Horst, R. L., J. P. Goff, and T. A. Reinhardt. 2005. Adapting to the transition between gestation and lactation: Differences between rat, human and dairy cow. J. Mammary Gland Biol. Neoplasia 10:141-156.

Iwersen, M., D. Klein-Jöbstl, M. Pichler, L. Roland, B. Fidlschuster, I. Schwendenwein, and M. Drillich. 2013. Comparison of 2 electronic cowside tests to detect subclinical ketosis in dairy cows and the influence of the temperature and type of blood sample on the test results. J. Dairy Sci. 96:7719-7730. 
Jawor, P. E., J. M. Huzzey, S. J. LeBlanc, and M. A. von Keyserlingk. 2012. Associations of subclinical hypocalcemia at calving with milk yield, and feeding, drinking, and standing behaviors around parturition in Holstein cows. J. Dairy Sci. 95:1240-1248.

Jonsson, N. N., M. R. McGowan, K. McGuigan, T. M. Davison, A. M. Hussain, M. Kafi, and A. Matschoss. 1997. Relationships among calving season, heat load, energy balance and postpartum ovulation of dairy cows in a subtropical environment. Anim. Reprod. Sci. 47:315-326.

Kamgarpour, R., R. C. Daniel, D. C. Fenwick, K. McGuigan, and G. Murphy. 1999. Postpartum subclinical hypocalcaemia and effects on ovarian function and uterine involution in a dairy herd. Vet. J. 158:59-67.

Kimura, K., T. A. Reinhardt, and J. P. Goff. 2006. Parturition and hypocalcemia blunts calcium signals in immune cells of dairy cattle. J. Dairy Sci. 89:2588-2595.

Lean, I. J., P. J. DeGaris, P. Celi, D. M. McNeill, R. M. Rodney, and D. R. Fraser. 2014. Influencing the future: Interactions of skeleton, energy, protein and calcium during late gestation and early lactation. Anim. Prod. Sci. 54:1177-1189.

LeBlanc, S. 2010. Monitoring metabolic health of dairy cattle in the transition period. J. Reprod. Dev. 56:S29-S35.

Lee, N. K., H. Sowa, E. Hinoi, M. Ferron, J. D. Ahn, C. Confavreux, R. Dacquin, P. J. Mee, M. D. McKee, D. Y. Jung, Z. Zhang, J. K. Kim, F. Mauvais-Jarvis, P. Ducy, and G. Karsenty. 2007. Endocrine regulation of energy metabolism by the skeleton. Cell 130:456-469.

Martín-Tereso, J., and H. Martens. 2014. Calcium and magnesium physiology and nutrition in relation to the prevention of milk fever and tetany (dietary management of macrominerals in preventing disease). Vet. Clin. North Am. Food Anim. Pract. 30:643-670.

Martinez, N., C. A. Risco, F. S. Lima, R. S. Bisinotto, L. F. Greco, E. S. Ribeiro, F. Maunsell, K. Galvão, and J. E. P. Santos. 2012. Evaluation of peripartal calcium status, energetic profile, and neutrophil function in dairy cows at low or high risk of developing uterine disease. J. Dairy Sci. 95:7158-7172.

Martinez, N., L. D. P. Sinedino, R. S. Bisinotto, R. Daetz, C. A. Risco, K. N. Galvão, W. W. Thatcher, and J. E. P. Santos. 2016. Effects of oral calcium supplementation on productive and reproductive performance in Holstein cows. J. Dairy Sci. 99:8417-8430.
Martinez, N., L. D. P. Sinedino, R. S. Bisinotto, E. S. Ribeiro, G. C. Gomes, F. S. Lima, L. F. Greco, C. A. Risco, K. N. Galvão, D. Taylor-Rodriguez, J. P. Driver, W. W. Thatcher, and J. E. P. Santos. 2014. Effect of induced subclinical hypocalcemia on physiological responses and neutrophil function in dairy cows. J. Dairy Sci. 97:874-887.

McDougall, S., R. Macaulay, and C. Compton. 2007. Association between endometritis diagnosis using a novel intravaginal device and reproductive performance in dairy cattle. Anim. Reprod. Sci. 99:9-23.

Murray, R. D., J. E. Horsfield, W. D. McCormick, H. J. Williams, and D. Ward. 2008. Historical and current perspectives on the treatment, control and pathogenesis of milk fever in dairy cattle. Vet. Rec. 163:561-565.

Neves, R. C., B. M. Leno, M. D. Curler, M. J. Thomas, T. R. Overton, and J. A. A. McArt. 2018. Association of immediate postpartum plasma calcium concentration with early-lactation clinical diseases, culling, reproduction, and milk production in Holstein cows. J. Dairy Sci. 101:547-555.

Neves, R. C., B. M. Leno, T. Stokol, T. R. Overton, and J. A. A. McArt. 2017. Risk factors associated with postpartum subclinical hypocalcemia in dairy cows. J. Dairy Sci. 100:3796-3804.

NRC. 2001. Nutrient Requirements of Dairy Cattle. 7th rev. ed. Natl. Acad. Press, Washington, DC.

Reinhardt, T. A., J. D. Lippolis, B. J. McCluskey, J. P. Goff, and R. L. Horst. 2011. Prevalence of subclinical hypocalcemia in dairy herds. Vet. J. 188:122-124.

Ribeiro, E. S., F. S. Lima, L. F. Greco, R. S. Bisinotto, A. P. A. Monteiro, M. Favoreto, H. Ayres, R. S. Marsola, N. Martinez, W. W. Thatcher, and J. E. P. Santos. 2013. Prevalence of periparturient diseases and impacts on fertility of seasonally calving grazing dairy cows supplemented with concentrates. J. Dairy Sci. 96:5682-5697.

Rodríguez, E. M., A. Arís, and A. Bach. 2017. Associations between subclinical hypocalcemia and postparturient diseases in dairy cows. J. Dairy Sci. 100:7427-7434.

Sepúlveda-Varas, P., D. M. Weary, M. Noro, and M. A. G. von Keyserlingk. 2015. Transition diseases in grazing dairy cows are related to serum cholesterol and other analytes. PLoS One 10:e0122317. https://doi.org/10.1371/journal.pone.0122317. 